\title{
Subject Index Vol. 154, 1995
}

Actin cytoskeleton 46

Activation 34

Adherensjunctions 46

Adhesion 21, 34

Adhesion-dependent signaling 46

Ageing 186

Agnatha 300

ATPase 216

Axon ensheathment 300

Bite block 205 Bone 128,272

Carotid body 143

Cartilage 272

Cat 128

Catagen 283

Cell adhesion molecules 243

migration 63

proliferation 283

signalling 21 Cell-matrix interactions 111 Chick 111, 169,267 Chief cell 143

Clavicle 128 Compact bone 181 Concanavalin A 120 Confocal microscopy 147

Development 99, 111, 120, 128, 169, 181,

243,261,267,272 Differentiation 79, 169 Dog 135

E-cadherin 8

Enteric neurons 243

Epiblast 79

Epididymis 186

Epithelial genes 8

Epithelial-mesenchymal interactions 111

- $\quad$ transformation/transition 5,8,21,63,

79,99, 111

Evolution 236 Extensor 216

Extracellular matrix 8,243 Eye 267

Facial growth 205

Fibroblast 267

Finger 216

Finger-like projections 196

Flexor 216

Focal adhesions 46 Foot 236

Gamma-aminobutyric acid 143 Gap junction 267 Gastrulation 79, 99 Gene control 21 Glia 300

Glycoconjugates 272 Golden hamster 186 Growth factors 8 
Hair cycle 283 - follicle 283 Haversian canal 181 Heart 111,169 Hirschsprung's disease 243 His, Wilhelm 167 Horse 196

Impregnation techniques 224 Infraorbital foramen 162 Ingression 79, 99 Integrins 34, 63

Intestine 243

Jaw joint 205

Keratin 283

Lamprey 300 Lectins, endogenous 272 Locational relationship 162 Loop-tail mutant 120

Macaque 216

Mast cell 267

Maturation 186

Mental foramen 162

Meriones unguiculatus 232

Mesenchymal genes 8

Mesoderm 99

Microfilaments 46

Miniature pig 205

Motor endplate 147

Mouse 120, 143

Multitendoned finger muscles 216

Muscle 216

Myocardial basement membrane 111

Myocardium 261

Myocyte 261

Myosin heavy chain 147

Nerve terminal 147

Neural cell adhesion molecule 120

- $\quad$ crest 63

Neuromuscular junctions 224 Nomina anatomica 167

Oncogenes 8 Osteon 181 Ovariectomy 135

Peptides 34 Photoperiod 283 Place-dependent expression 21 Primitive streak 79 Proanagen 283

Proliferation 169

Rabbit 99

Rat $147,224,243,261$

Sarcoplasmic reticulum 224 Schwann cells 300 Sheep 128,283 Signalling 34 Sinus hair 196

Spaceflight 169 Specialisations 300 Sperm, abnormal 186 Spinal cord 120

- $\quad$ transection 147

Stereology 135,261

Subcommissural organ 232

Supraorbital notch/foramen 162

Sutures 205

Symphalangism 236

Terminology 167

TGF-ß family 63

Three-dimensional reconstructions 224

Toes 236

Trabeculae 196 
Tyrosine phosphorylation 46

Urethra 135

Urinary incontinence 135

Ventricular ependyma 232 Vibrissae 196

WilhelmHis 167 Wool 283

316 